\title{
Optimizing Chronic HIV Care in the Dutch Caribbean: A Questionnaire Based Study on Experience and Perception of Healthcare Workers
}

\author{
HS Hermanides ${ }^{1}$, JO Busari ${ }^{2}$, I Gerstenbluth ${ }^{3}$, AJ Duits ${ }^{1,4}$
}

\begin{abstract}
Objective: Human immunodeficiency virus (HIV) infection has become a chronic disorder for which adaptation of current healthcare practices is needed. In Curaçao, a new organization of chronic HIV care is being set up based on task shifting in which healthcare workers (HCWs) will deliver HIV care more prominently within the primary healthcare system. In preparation for implementation of the proposed task-shifting model, we investigated the perception of HCWs regarding existing HIV care in Curaçao and the need for training in HIV/AIDS among HCWs.

Subjects and Methods: An in-depth questionnaire based study was used. Nineteen HCWs of seven different cadres were interviewed. The questionnaire constituted four sections: quality of existing HIV care, respondents own knowledge and willingness to be trained, need for training in HIV/AIDS and preferred educational approaches.

Results: Quality of existing HIV services in Curaçao is considered acceptable but needs improvement mainly to facilitate integration of chronic HIV care. All respondents indicated that training in HIV/AIDS is needed among HCWs in Curaçao, especially for nurses and general practitioners. All were willing to participate in training with varying amounts of time to be spent. Training should be tailored to the level of expertise of HCWs and to the role a HCW is expected to have in the new healthcare delivery framework.

Conclusion: There is need for training to ensure the effective integration of chronic HIV care into the existing healthcare delivery system in Curaçao. There is a willingness and need in all cadres for training with e-learning as a preferred educational tool.
\end{abstract}

Keywords: Chronic HIV care, questionnaire, perception of healthcare workers

\section{Optimización del Cuidado del VIH Crónico en el Caribe Holandés: Un Estudio Basado en un Cuestionario sobre la Experiencia y la Percepción de los Trabajadores de la Salud}

HS Hermanides ${ }^{1}$, JO Busari² ${ }^{2}$ I Gerstenbluth ${ }^{3}$, AJ Duits ${ }^{1,4}$

\begin{abstract}
RESUMEN
Objetivo: La infección por virus de inmunodeficiencia humana (VIH) se ha estado convirtiendo en un trastorno crónico que requiere la adaptación de las prácticas actuales de salud. En Curazao, se ha estado creando una nueva organización de la atención del VIH crónico, basada en un cambio de tareas en las que los trabajadores de la salud (TS) brindarán un cuidado prominente al VIH dentro del sistema primario de atención a la salud. En preparación para la implementación del modelo de cambio de tareas propuesto, investigamos la percepción de los TS en relación con la atención actual al VIH en Curazao y la necesidad de capacitación en torno al VIH/SIDA entre los TS.

Sujetos y métodos: Se utilizó un estudio basado en un cuestionario detallado. Se entrevistaron diecinueve TS de siete cuadros diferentes. El cuestionario estaba constituido por cuatro secciones:
\end{abstract}

From: ${ }^{1}$ Red Cross Blood Bank Foundation, Willemstad, Curaçao, ${ }^{2}$ Atrium Medical Centre Parkstad, Heerlen, the Netherlands, ${ }^{3}$ Epidemiology and Research Unit, Medical and Public Health Services of Curaçao, Willemstad, Curaçao, The Netherland Antilles, and ${ }^{4}$ University Medical Centre Groningen (Institute for Medical Education) and University of Groningen, the Netherlands.
Correspondence: Dr AJ Duits, Red Cross Blood Bank Foundation, Pater Eeuwensweg 36, Willemstad, Curaçao, The Netherland Antilles. Fax: 59994618431, e-mail: ajduits@gmail.com 
calidad del cuidado existente al VIH, conocimiento y voluntad de los propios encuestados para recibir capacitación en la atención al VIH/SIDA, y los enfoques educativos preferidos.

Resultados: Calidad de los servicios del VIH existentes en Curazao se considera aceptable pero necesita mejorar principalmente en cuanto a facilitar la integración de la atención del VIH crónico. Todos los encuestados indicaron que se necesita capacitación en VIH/SIDA entre los TS de Curazao, especialmente para las enfermeras y médicos generales. Todos estaban dispuestos a participar en el entrenamiento, siendo variable la cantidad de tiempo a emplear en el mismo. La capacitación se debe diseñar de acuerdo con el nivel de conocimientos de los TS, y el papel que se espera que un TS desempeñe en el nuevo marco de cuidados de la salud.

Conclusión: Hay necesidad de entrenamientos para integrar de manera efectiva la atención al VIH crónico al sistema actual de servicios de cuidados de la salud en Curazao. Todos los cuadros tienen la voluntad y la necesidad de recibir capacitación en esta área, para lo cual el aprendizaje electrónico es la herramienta educativa de preferencia.

Palabras claves: Cuidado del VIH crónico, cuestionario, percepción de los trabajadores de la salud

West Indian Med J 2013; 62 (4): 300

\section{INTRODUCTION}

One of the major constraints in improving the management of human immunodeficiency virus (HIV) care is the limited human resource availability (1). To combat this lack of human resources, the World Health Organization (WHO) developed an interim guideline based on task-shifting, aimed at facilitating the rapid scaling-up of antiretroviral therapy (cART) in resource constrained settings and integrating HIV care in primary healthcare (PHC) delivery systems (2).

Task-shifting is defined as a process of delegation whereby tasks are appropriately moved to healthcare workers (HCWs) with lower qualification requiring specific training (3). A similar task-shifting approach seems recommendable in order to better accommodate chronic HIV care in existing treatment programmes (4).

In the pre-cART era, acute HIV care in small Caribbean settings like Curaçao could satisfactorily be managed by a few healthcare providers. However, as HIV infection is becoming a chronic disorder, an integrated management approach is needed within the PHC (5). Curaçao is a Dutch Caribbean island with approximately 140000 inhabitants and an estimated HIV infection prevalence of $0.61 \%-1.05 \%$ (6). Care for patients (including cART provision) is provided by a single physician at the St Elisabeth Hospital. A recent report on cART outcome in Curaçao showed late clinical presentations, high rates of lost to follow-up and a low virological response in HIV-1 infected individuals (7). In order to integrate HIV care into the current PHC delivery system of Curaçao, task-shifting to different cadres of healthcare providers should seriously be considered. It is well documented that specific training programmes tailor-made to the local context, perspectives, training needs and addressing existing professional barriers are of importance for successful taskshifting (8).

To effectively prepare for and facilitate the implementation of a task-shifting model, we examined the per- ception and experience of $\mathrm{HCWs}$ regarding the current status in Curaçao of HIV care and concomitant training needs.

\section{SUBJECTS AND METHODS}

Task-shifting requires the transfer of specific clinical responsibilities to other HCWs who need to be appropriately trained for the tasks. In our case, task-shifting was aimed at integrating HIV care into the PHC delivery system, involving the participation of several cadres in HIV care. A potential model for Curaçao was developed by the authors and is shown in the Figure.

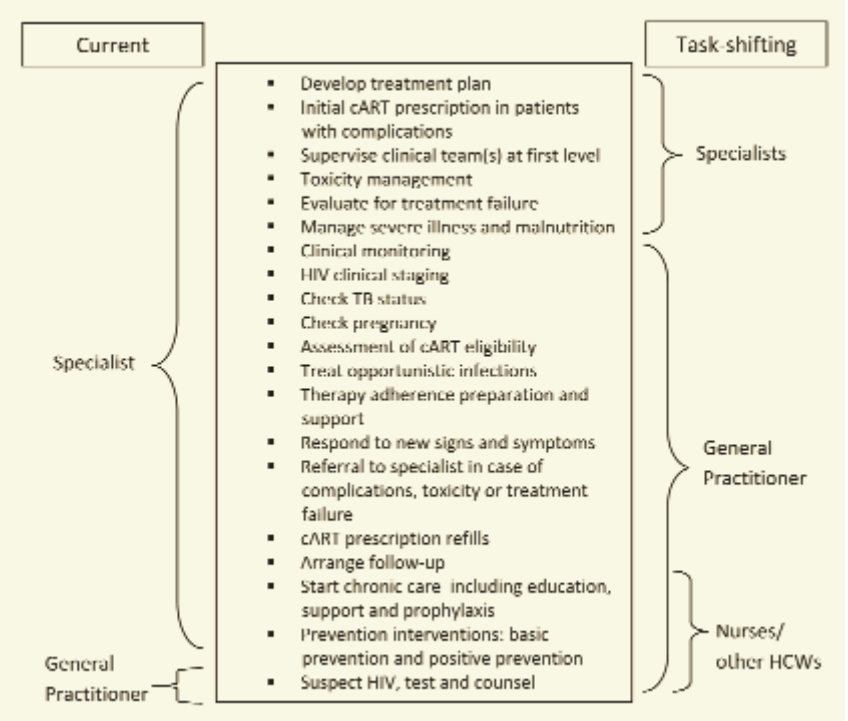

Figure: Current model of HIV care in Curaçao and the task-shifting model where chronic HIV care is based within the primary healthcare structure near the patient's home. [Based on Chronic HIV care with ARV therapy and prevention: integrated management of adolescent and adult illness guideline. WHO; 2007 (22)] 
To effectively prepare for the implementation of the proposed task-shifting model, a qualitative study was conducted among HCWs to whom certain tasks would be delegated. An in-depth questionnaire was designed by the authors and used to investigate the perception and experience of HCWs regarding the existing HIV care and their training needs. The creation and selection of the items for the questionnaire were based on consensus and with specific input from the educator and epidemiologist involved in the study. The final items that were included in the questionnaire were determined based on the outcome of a Delphi-like consultation with HCWs. The HCWs and cadres were selected as a result of a prior HIV workshop on healthcare delivery.

The questionnaire consisted of four sections. In the first section, respondents were asked to rate quality of existing HIV care (on a Likert scale from 1 to 10 ) and to explain their rating. The second section included questions about respondents' knowledge and training needs and their attitude toward their task in HIV care. In the third section, respondents were asked to rate the need for training of six different cadres of HCWs involved in HIV services in Curaçao using a Likert scale (1 not necessary; 5 very necessary). Total scores were taken to define the cadres that mostly needed training in HIV/AIDS. Medians and ranges were calculated to define respectively overall scores and the consensus per cadre. In the last section they were asked to define the most appropriate educational approaches and topics for training in HIV/ AIDS.

The interviews were semi-structured ie the conversations were guided by pre-defined questions that needed to be asked (Appendix). During the interview, two interviewers literally wrote down answers. The analysis took place in a cyclic process wherein, per item, established themes and text parts were coded and described. These codes and described text parts were categorized according to their similarities. Relations were established after discussion by the educator and the researcher (JB and $\mathrm{HH}$, respectively).

\section{RESULTS}

Nineteen HCWs of seven different cadres were interviewed individually. Table 1 shows baseline characteristics of the respondents. Six respondents were already involved in daily HIV care, of which three provided prevention services through non-governmental organizations (NGOs), one $\mathrm{HCW}$ provided cART, one distributed cART and one was responsible for policy-making. Only one general practitioner (GP) reported not being involved in HIV care at all, considering HIV care to be specialized medical care.

\section{Section 1: Quality of existing HIV care}

The respondents rated the quality of HIV care in Curaçao with a median of 7.0 [interquartile range (IQR), 5.8-7.5] (Table 1). Two respondents indicated that HIV care could be improved, but did not know how. The respondent who gave a score of 2.5 provided several reasons: a lack of collabora-
Table 1: Baseline characteristics of respondents who participated in the survey

\begin{tabular}{lrrr}
\hline & & $\mathbf{N}$ & \%/IQR \\
\hline $\begin{array}{lrr}\text { Number } \\
\text { Female }\end{array}$ & & 19 & \\
Involvement in HIV care & & 7 & $36.8 \%$ \\
& Daily & 6 & $31.5 \%$ \\
& $\begin{array}{l}\text { Frequently } \\
\text { Sometimes }\end{array}$ & 3 & $15.8 \%$ \\
& Never & 1 & $42.1 \%$ \\
Knowledge of HIV/AIDS & & & $5.2 \%$ \\
& Median & 6.3 & $6.0-7.0$ \\
Quality of HIV services & & & \\
& Median & 7.0 & $5.8-7.5$ \\
\hline
\end{tabular}

tion between/within different HCW groups involved in HIV care, non-sustainability of current HIV care with only one provider, lack of central coordination, and poor access to cART for the uninsured or undocumented immigrants due to high costs (Table 2).

Table 2: Suggestions given by interviewees to improve quality of HIV care in Curaçao

\begin{tabular}{ll}
\hline Suggestions to improve HIV care in Curaçao & N \\
\hline Integration of HIV care & 4 \\
Increase information for the general population & 4 \\
Central coordination of HIV care & 3 \\
Updating knowledge among HCWs and population & 3 \\
Improving access to cART, cost reductiona and provision of & \\
free access to undocumented immigrants & 3 \\
Do not know how & 2 \\
Decrease discrimination and stigma, not further specified & 2 \\
Better collaboration between different cadres & 2 \\
Surveillance, active follow-up of PLWH & 1 \\
More prominent role of public health in coordination & 1 \\
Increase education in HIV among physicians & 1 \\
More political involvement & 1 \\
Patient centred care focusing on adherence & 1 \\
Specialized HIV nurse & 1 \\
Increase research, a current lack of data & 1 \\
Centralized clinic for HIV care with specialized nurses & 1
\end{tabular}

HIV- human immunodeficiency virus; HCWS - healthcare workers; cARTantiretroviral therapy; PLWH- people living with HIV

\section{Section 2: Respondents' knowledge and willingness to be trained}

All interviewees indicated a need for personal training in HIV/AIDS with time willing to be spent ranging from two hours per year to unlimited (with respondents currently more involved in HIV care willing to spend more time than those less involved). The main reasons for their training need included: knowledge update $(\mathrm{n}=5)$, lack of information on specific topics related to their area of expertise $(n=4)$, very dynamic nature of the disease $(n=2)$ and 'never know enough' $(n=2)$. Rated on a scale from $1-10$, the interviewees rated their personal knowledge with a median of 6.3 [IQR, 6.0 - 7.0] (Table 1). 


\section{Section 3: HIV training for different cadres}

All respondents indicated that training in HIV/AIDS is necessary among HCWs in Curaçao. The main reason given was that knowledge of HIV care among HCWs was not up to date $(\mathrm{n}=5)$ and that general knowledge of HIV/AIDS was lacking at every level of healthcare $(n=3)$. Another reason indicated by interviewees $(n=5)$ was the necessity to change from current centralized HIV care (one treating physician) toward integration into $\mathrm{PHC}$ because of better sustainability $(\mathrm{n}=2)$ and quality of chronic care $(\mathrm{n}=3)$ ie early detection of side effects and non-compliance. Three interviewees responded that education among HCWs in Curaçao was needed to change the attitude of HCWs toward people living with HIV/AIDS (PLWHA) and to address stigma and discrimination. Eleven respondents indicated that training is necessary for their own cadre. Two interviewees responded that next to their own cadre, every cadre in the healthcare sector needs training in HIV/AIDS. Six respondents indicated that other cadres had a higher need for training than their own cadre, namely PHC workers $(n=3)$ and nurses and personnel of nursing homes $(\mathrm{n}=3)$.

All interviewees were asked to score the necessity of HIV training for six cadres to whom certain tasks would be delegated according to the proposed task-shifting model (GPs, medical specialists, NGOs, nurses, laboratory personnel and pharmacists). All cadres scored a median of 5 (out of 5), except for laboratory personnel $($ median $=4$ ). The highest total score with the smallest range was given to nurses and GPs (total 87 (range $=4-5$ ) and $84(3-5$ ), respectively) compared to medical specialists, pharmacists, laboratory personnel and NGO personnel (total 82 (range $=$ $2-5), 78(2-5), 76(2-5)$ and $76(1-5)$, respectively).

The main reason that was given for scoring nurses and GPs as the most important group in need of training was because of their 'daily and direct involvement in HIV care'. Remarkably, three GPs did not judge themselves as the most important group for getting training as they indicated they had no role in current HIV care at all.

Other cadres of HCWs in need of HIV training not mentioned in the questionnaire but proposed by the interviewees were social workers ( $n=5)$, visiting nurses $(n=4)$, midwives $(\mathrm{n}=3)$, ambulance personnel $(\mathrm{n}=2)$, psychologists $(n=2)$, dentists $(n=2)$, public health workers $(n=2)$, dieticians $(\mathrm{n}=1)$, paramedical personnel $(\mathrm{n}=1)$, physical therapist $(\mathrm{n}=1)$, hospital personnel $(\mathrm{n}=1)$, and emergency department personnel $(n=1)$.

Apart from professionals in the healthcare sector, the interviewees indicated that the general population $(n=6)$, school teachers $(n=4)$, police department $(n=2)$, family and friends of PLWH $(n=1)$, the fire brigade $(n=1)$, barber or hair stylists $(\mathrm{n}=1)$, insurance companies $(\mathrm{n}=1)$ and media $(\mathrm{n}=1)$ needed HIV training. The main reasons given were: to decrease discrimination and stigmatization of PLWH and to better inform persons in order to prevent HIV infection.

\section{Section 4: Educational approaches and topics}

According to the interviewees, the topics for HIV/AIDS training depend on the expertise or cadre of the HCW with the most important topics being antiretroviral therapy, side effects and interaction of cART $(n=10)$, prevention of HIV infection $(n=7)$, general knowledge of HIV/AIDS $(n=7)$ and training in social and attitude aspects $(\mathrm{n}=3)$.

The preferred learning methods were: e-learning $(\mathrm{n}=$ $5)$, a conference $(n=4)$, an interactive course $(n=3)$, combined e-learning with interactive courses $(\mathrm{n}=3)$, conferences combined with interactive courses $(n=2)$, an exchange programme combined with interactive courses $(\mathrm{n}=1)$ and all kind of methods $(n=1)$. One interviewee mentioned that a central organization should be responsible for training and quality control of the knowledge of HCWs providing HIV services to prevent involvement/participation of unqualified personnel. There was no relationship observed between the preferred learning method and the expertise or the level of involvement in HIV care of the interviewee.

\section{DISCUSSION}

In contrast to developing countries (especially sub-Saharan Africa) where, because of severe shortage of HCWs, taskshifting is used to rapidly scale-up access to HIV care and treatment $(1,9)$, Curaçao requires task-shifting for integrating HIV care into PHC in order to better address the increasing chronic nature of the disease, improve the quality and optimize the efficacy of cART (10). To assist and facilitate this process, it seemed important to examine the perception and attitude of HCWs on HIV care.

The study had four major findings: training in HIV is perceived to be necessary among HCWs in Curaçao, there is a willingness of HCWs to participate in training, training in HIV should be tailored to the level of expertise of HCWs and quality of existing HIV services is considered acceptable but needs improvement mostly by integration into PHC and in communication among HCWs. This is, to our knowledge, one of the first studies describing the perspective of HCWs toward training and task shifting in HIV care.

Albeit critics have urged caution about maintaining quality of care when shifting tasks to lower cadres, there is growing evidence of maintained or even improved quality outcome when shifting tasks to PHC especially in early diagnosis and care retention (9-16). Of importance is the observation that effective performance by task-shifted workers has occurred in an environment of in-depth training and ongoing support (8).

Although an individual willingness of all interviewees to participate in training was observed, not all indicated that the training was highest priority for their own cadres. The findings show that training seems most needed for nurses and GPs as those cadres are involved in daily care of PLWH and have through the years been delegated with increasing responsibilities in HIV care, supporting existing literature (5). 
Remarkably in our study, GPs did not identify their cadre as the most important to be trained in HIV care. Mainly because they felt that they had little or no responsibilities in HIV care compared to other cadres of HCWs. Bodenheimer et al already reported that the chronic care model constitutes a major rethinking of primary care practice (17). Therefore, this rethinking is essential when planning for task-shifting. Task-shifting can only be effective if all roles and responsibilities are clearly defined and accepted, including tasks for community health workers, family members and patients (13).

Our results also indicate that training aimed to implement task-shifting should be tailored to the level of expertise, the level of involvement and the tasks of HCWs in current and future HIV care programmes as also suggested by others (18). A previous report showed that training in HIV/ AIDS in Curaçao that is aimed in part to increase efficacy of cART should at least be targeted toward the early identification and rapid referral of PLWH. In addition, it should also aim to improve adherence and compliance to therapy and retention of care as reported in several studies $(7,8)$.

Interestingly, e-learning was considered a valuable training tool by most participants. The promising results obtained in several developing countries with e-learning programmes support the potential positive impact of such an educational approach $(19,20)$.

Only a few studies, focussed on specific areas of HIV related care, have been published on task-shifting in the Caribbean. Mukherjee et al showed the successful effect of task-shifting by involving community HCWs in providing medical therapy and emotional support to PLWH in Haiti. In this study, the roles of HCWs in the delivery of HIV care was to identify vulnerable groups and facilitate use of PHC services (10). Another study described how nursing interventions formed a key feature in the ongoing development and success of a prevention of mother-to-child HIV transmission programme in Jamaica with a strong necessity for continuous education and training (11). No information on the HCWs' initial perspectives and attitudes and how this influenced training and the task-shifting design was reported. Further underscoring the objective and results of this study, the lack of thorough analysis of the professional view and barrier to policy change is considered an important gap in current task-shifting design (8).

When shifting some clinical responsibilities to nurses, GPs and other HCWs, we must consider the modified role of the medical specialist, who will provide care for patients with complications and at the same time support and guide patient management by others. As proposed by one of the interviewees, a national committee should be responsible for monitoring and evaluating the level of knowledge and skills of HCWs working in HIV care to assure quality of care. In addition, a comprehensive training programme for initial and continuous education should be developed as part of a national HIV/AIDS management plan. Furthermore, stan- dardized protocols, adapted medical records and tools to assist HCWs to perform HIV care are pivotal in implementing task-shifting and achieving the proposed goals. Given the current organization of HIV care with the availability of only one expert for care and treatment in Curaçao, pure taskshifting without strengthening the current HIV care programme will not be feasible and investment in human capital is required.

A limitation of this study could be the response recording, which was written rather than audiotaped. However, text phrases were literally written down to prevent misinterpretation. Also, the selection of interviewees was based on HCWs currently involved in HIV care and cadres of HCWs involved in the proposed task-shifting model. Although not included, studies on the perspectives of relatives of PLWHA will also be of importance, especially because of the importance of patient self-management in chronic care management.

Constant critical analysis of successful, sustainable and cost-effective implementation models remains of importance (21).

\section{ACKNOWLEDGMENTS}

The authors would like to thank all healthcare workers who participated in the study. This study was supported by a generous grant of the Netherlands Antillean Foundation for Higher Clinical Education (NASKHO).

\section{REFERENCES}

1. Van Damme W, Kober K, Laga M. The real challenges for scaling up ART in sub-Saharan Africa. AIDS 2006; 20: 653-6.

2. World Health Organization. Integrated management of adolescent and adult illness (IMAI). World Health Organization. Available from: http:// www.who.int/hiv/pub/imai/en/

3. World Health Organization. Task shifting: rational redistribution of tasks among health workforce teams: global recommendations and guidelines. Geneva: World Health Organization; 2008 [Accessed 2008 Feb 6]. Available from: http://www.who.int/healthsystems/TTR-Task Shifting.pdf

4. Dohrn J, Nzama B, Murrman M. The impact of HIV scale-up on the role of nurses in South Africa: time for a new approach. J Acquir Immune Defic Syndr 2009; 52 (Suppl 1): S27-9.

5. Beaglehole R, Epping-Jordan J, Patel V, Chopra M, Ebrahim S, Kidd M et al. Improving the prevention and management of chronic disease in low-income and middle-income countries: a priority for primary health care. Lancet 2008; 372: 940-9.

6. Lourents N, Gerstenbluth I. HIV/AIDS surveillance Netherlands Antilles from 1985 thru December 31, 2007. Epidemiology and Research Unit, Medical and Public Health Survice of Curaçao; 2008.

7. Hermanides HS, Gras L, Winkel CN, Gerstenbluth I, van Sighem A, de Wolf $\mathrm{F}$ et al. The efficacy of combination antiretroviral therapy in HIV type 1-infected patients treated in Curaçao compared with Antillean, Surinam, and Dutch HIV type 1-infected patients treated in The Netherlands. AIDS Res Hum Retroviruses 2011; 27: 605-12.

8. Callaghan M, Ford N, Schneider H. A systematic review of taskshifting for HIV treatment and care in Africa. Hum Resour Health 2010; 8: 8 .

9. Sherr K, Pfeiffer J, Mussa A, Vio F, Gimbel S, Micek M et al. The role of nonphysician clinicians in the rapid expansion of HIV care in Mozambique. J Acquir Immune Defic Syndr 2009; 52 (Suppl 1): S203. 
10. Mukherjee JS, Eustache FE. Community health workers as a cornerstone for integrating HIV and primary healthcare. AIDS Care 2007; 19 (Suppl 1): S73-82.

11. Palmer PM, Anderson-Allen MM, Billings CC, Moore JT, McDonaldKerr C, Steel-Duncan JC et al. Nursing interventions in the Kingston Paediatric and Perinatal HIV/AIDS Programme in Jamaica. West Indian Med J 2004; 53: 327-31.

12. Cooke GS, Little KE, Bland RM, Thulare H, Newell ML. Need for timely paediatric HIV treatment within primary health care in rural South Africa. PLoS One 2009; 4: e7107.

13. Shumbusho F, van Griensven J, Lowrance D, Turate I, Weaver MA, Price J et al. Task shifting for scale-up of HIV care: evaluation of nursecentered antiretroviral treatment at rural health centers in Rwanda. PLoS Med 2009; 6: e1000163.

14. Morris MB, Chapula BT, Chi BH, Mwango A, Chi HF, Mwanza J et al. Use of task-shifting to rapidly scale-up HIV treatment services: experiences from Lusaka, Zambia. BMC Health Serv Res 2009; 9: 5

15. Bedelu M, Ford N, Hilderbrand K, Reuter H. Implementing antiretroviral therapy in rural communities: the Lusikisiki model of decentralized HIV/AIDS care. J Infect Dis 2007; 196 (Suppl 3): S4648.

16. Cohen R, Lynch S, Bygrave H, Eggers E, Vlahakis N, Hilderbrand K et al. Antiretroviral treatment outcomes from a nurse-driven, communitysupported HIV/AIDS treatment programme in rural Lesotho: observational cohort assessment at two years. J Int AIDS Soc 2009; 12: 23.

17. Bodenheimer T, Wagner EH, Grumbach K. Improving primary care for patients with chronic illness. JAMA 2002; 288: 1775-9.

18. Mullan F, Frehywot S. Non-physician clinicians in 47 sub-Saharan African countries. Lancet 2007; 370: 2158-63.

19. Deane G, Picou D, Archibald L, Lum Lock A, Phillip E, Ali Z. Using elearning to up-skill healthcare providers in Trinidad and Tobago. West Indian Med J 2011; 60 (Suppl 2): 52.

20. Health [e] Foundation. Annual Report 2010. Available from: www. healthefoundation.eu

21. Samb B, Celletti F, Holloway J, Van Damme W, De Cock KM, Dybul M. Rapid expansion of the health workforce in response to the HIV epidemic. N Engl J Med 2007; 357: 2510-4.

22. World Health Organization. Chronic HIV care with ARV therapy and prevention: integrated management of adolescent and adult illness guideline. Geneva: World Health Organization; 2007.
Appendix: Guidance of pre-defined topics to be asked during the semistructured interviews.

\section{Involvement in HIV care}

Need for training in HIV/AIDS among HCWs in Curaçao:

NGOs

Specialists

General practitioners

Nurses

Laboratory personnel

Pharmacy personnel

Other HCWs

Non HCWs

Topics of training in HIV/AIDS

Method of training in HIV/AIDS

Personal need for training

Time willing to invest

Improvement in quality of HIV care in Curaçao

Rating:

Personal knowledge of HIV/AIDS

Personal quality of HIV care

Quality of HIV care in Curaçao

HIV - human immunodeficiency virus; AIDS - acquired immunodeficiency syndrome; NGOs - non-governmental organizations; HCWs - healthcare workers 